\title{
CONDUTIVIDADE ELÉTRICA E LIXIVIAÇÃO DE POTÁSSIO DO EXSUDATO DE GRÃOS DE CAFÉ: ẢLGUNS FATORES QUE PODEM INFLUENCIAR ESSAS AVALIAÇÕES ${ }^{1}$
}

\author{
Potassium leaching and eletric conductivity of grain coffee (Coffea arabica L.) \\ exsudate: some factors that may affect these evaluations
}

\author{
Marcelo Ribeiro Malta ${ }^{1}$, Rosemary Gualberto Fonseca Alvarenga Pereira² ${ }^{2}$ Sílvio Júlio de Rezende Chagas ${ }^{3}$
}

\begin{abstract}
RESUMO
Os procedimentos de avaliação comercial da qualidade do café são baseados em parâmetros subjetivos, pois dependem de sensações e habilidades pessoais, adquiridas com muitos anos de experiência. Assim, a complementação dos procedimentos em uso com a adoção de métodos físicos e químicos tornaria mais objetiva a determinação da qualidade do café. A determinação da condutividade elétrica e da lixiviação de potássio dos grãos tem sido considerada por vários pesquisadores como bons indicadores da integridade do sistema de membranas celulares. Porém, vários fatores podem influenciar essas avaliações. Diante desse contexto foi montado um experimento para avaliar alguns fatores que podem influenciar na determinação da condutividade elétrica e lixiviação de potássio de exsudatos de grãos de café. Neste trabalho, estudou-se a influência do tamanho dos grãos e dos tipos de defeitos na determinação da condutividade elétrica e a lixiviação de potássio. Amostras de café (Coffea arabica L), cultivar Acaiá do Cerrado MG 1474 foram submetidas a estas análises. Em relação ao tamanho dos grãos de café sem a retirada de defeitos, verificou-se que as menores peneiras apresentaram maiores valores de condutividade elétrica e lixiviação de potássio, o que não foi observado quando se retiraram os defeitos dessas amostras. Em relação aos defeitos verificou-se a seguinte ordem crescente de condutividade elétrica: grãos normais, verdes, brocados e ardidos semelhantes aos pretos. Em relação à lixiviação de potássio, verificou-se o mesmo comportamento, com exceção dos grãos verdes e brocados que apresentaram valores semelhantes. A presença de grãos defeituosos influencia de maneira significativa as determinações de condutividade elétrica e lixiviação de potássio de exsudatos de grãos, podendo fornecer interpretações inadequadas quanto à qualidade do café analisado.
\end{abstract}

Termos para indexaçäo: Qualidade do café, lixiviação de potássio e condutividade elétrica, Coffea arabica.

\begin{abstract}
Commercial coffee (Coffea arabica L.) quality evaluation procedures are based on subjective parameters, once depend on personal abilities and sensitivity, acquired after many years of experience. So in order to complement these analysis physical and chemical methods are also used to support the results. Firstly an experiment was installed to evaluate some factors that may influence in grain coffee exsudates, potassium leaching and electric conductivity determination. Grain coffee size and defects affect potassium leaching and electric conductivity in coffee cultivar, Acaia Cerrado MG 1474. A coffee grain sample, with no defective grain removal showed at the lower sieves, higher eletric conductivity and potassium leaching values. However, pulling back defective grains those values were not observed. There was a gradative increase in electric conductivity in grain coffee as follow: normal, greens and bored grains and also fermented as black grains. In relation to potassium leaching there were no differences, excepted to green and bored grains that had similar values. These results suggest that defective coffee grain might affect in significant way the electric conductivity and potassium leaching of esxudate of grains, and could cause inadequate interpretations related to quality of the analyzed coffee.
\end{abstract}

Index terms: coffee quality, potassium leaching, conductivity eletric, Coffea arabica.

(Recebido para publicação em 18 de outubro de 2004 e aprovado em 20 de maio de 2005)

\section{INTRODUÇÃO}

Os atuais procedimentos para avaliação comercial da qualidade do café estão baseados em características subjetivas, pois dependem de sensações e habilidades pessoais dos provadores, adquiridas com muitos anos de experiência. Apesar da análise sensorial ser a metodologia adotada pela Organização Internacional do Café (OIC), esta, por ser subjetiva, é sujeita a críticas (CHAGAS, 1994;
CORTEZ, 1997). Assim, a complementação dos procedimentos em uso com a adoção de métodos físicos e químicos tornaria mais real e objetiva a determinação da qualidade do café (PRETE, 1992).

Inúmeras pesquisas buscam responder do ponto de vista químico quais substâncias determinam na bebida a aceitação ou rejeição e quais são os precursores e as reações que resultam nessas substâncias desejáveis ou não no grão cru de café (CLIFFORD, 1985). Entretanto, a

\footnotetext{
1 Doutorando do curso de Ciência dos Alimentos/UFLA - Cx. P. 176 - 37200-000 - maltamarcelo@uol.com.br

2 Professor Adjunto, Departamento de Ciência dos Alimentos/UFLA - Cx. P. 3037 - 37200-000

${ }^{3}$ Pesquisador Dr., Empresa de Pesquisa Agropecuária de MinasGerais - Cx. P. $176-37200-000$
} 
composição química do grão de café cru depende da interação genótipo e ambiente e das condições de manejo para produção e processamento após a colheita (CARVALHO et al., 1997). O grão de café cru não possui o aroma nem o sabor típicos da bebida do café, assim a torração é essencial para a formação de compostos responsáveis pelo sabor e aroma do produto final. Há ainda que se considerar as interações entre os compostos durante o preparo da bebida e as complexas interações dentro da boca, entre os compostos químicos do café e as substâncias salivares, sem falar dos estímulos aos processos mentais que esta bebida provoca. Isto posto, verifica-se a complexidade em se relacionar qualidade da bebida com a composição química do grão de café cru (PRETE, 1992). Ainda segundo este autor, há mecanismos complexos e interdependentes no processo de deterioração do grão de café que nenhuma teoria simples poderia fornecer explicações definitivas e permitir afirmações taxativas sobre o que é, na realidade, resultado de uma somatória de eventos. Existe uma concordância de que a degeneração das membranas celulares e subseqüente perda de controle de permeabilidade, seja um dos primeiros eventos que caracterizam a deterioração. Para Amorim (1978), qualquer fator que altere a estrutura da membrana, como ataque de insetos e microrganismos, alterações fisiológicas e danos mecânicos, provocam uma rápida deterioração dos grãos de café. Essas alterações provocam reações químicas que modificam a composição química original do grão de café verde e em consequiência as propriedades sensoriais da infusão preparada.

Desta forma, testes para avaliar a qualidade de sementes baseados na perda de integridade das membranas foram desenvolvidos. Nestes trabalhos as sementes são imersas em água e durante o processo de embebição, de acordo com o grau de integridade de suas membranas, lixiviam solutos citoplasmáticos no meio líquido. Os solutos, com propriedades eletrolíticas possuem cargas elétricas que podem ser medidas com condutivímetro. Assim, sementes de baixo vigor liberam grande quantidade de eletrólitos na solução, resultando em alto valor de condutividade elétrica (BEDFORD, 1974; WOODSTOCK, 1973) ou em elevadas concentrações de determinados íons, principalmente potássio (MARCOS FILHO et al., 1990; PRETE,1992).

Prete (1992) verificou uma relação inversa entre a qualidade da bebida e a condutividade elétrica e a lixiviação de potássio de exsudatos de grãos crus. Baseado nessa hipótese, Romero et al. (2003) utilizaram a metodologia para determinação da condutividade elétrica proposta por Prete (1992), para a separação de 18 cultivares de Coffea arabica
L., chegando a conclusão que seria possível separar esses diferentes genótipos quanto a sua qualidade (bebida) mediante esta análise. Entretanto, segundo Favarin et al. (2004), esses testes não se correlacionam com a análise sensorial da bebida (padrão).

Apesar dos esforços realizados até agora, a interpretação da leitura da condutividade elétrica dos exsudatos liberados pelas sementes ainda precisa de estudos mais detalhados (GOTARDO et al., 2001). Assim, para que testes baseados na integridade das membranas celulares como a condutividade elétrica apresente resultados uniformes, consistentes e reprodutíveis recomenda-se especial atenção para alguns fatores que podem afetar essas determinações como, por exemplo, o teor de umidade inicial e uniformidade da amostra (LOEFFLER et al., 1988); tempo de embebição e temperatura (LOEFFLER et al., 1988; MARCOS FILHO et al., 1990), tipo e número de defeitos presentes e tamanhos dos grãos de café (PRETE, 1992), dentre outros.

Baseado no exposto, objetivou-se com este experimento avaliar a influência do tamanho de grãos e tipos de defeitos na determinação da condutividade elétrica e lixiviação de potássio de exsudatos de grãos de café.

\section{MATERIAL E MÉTODOS}

\section{Caracterização do experimento}

O lote de grãos de café obtido para realização das análises foi colhido em lavoura cafeeira (Coffea arabica L.) cultivar Acaiá Cerrado MG 1474, por derriça manual no pano, safra 2003/04 em experimento conduzido no setor de engenharia agrícola da Universidade Federal de Lavras/MG. Foi realizada uma classificação prévia desse lote de café, sendo classificado como tipo 6-45, bebida dura, com teor de umidade médio de $10,7 \%$. Todas as avaliações nos grãos de café foram conduzidas no Laboratório de Qualidade do Café "Dr. Alcides Carvalho", da Empresa de Pesquisa Agropecuária de Minas Gerais, situado em Lavras/MG.

$\mathrm{O}$ delineamento experimental adotado foi inteiramente casualizado, com quatro repetições em esquema fatorial, disposto da seguinte forma: Fator 1 Tamanhos dos grãos de café; Fator 2 - Grãos defeituosos.

\section{Método analítico}

\section{Teor de água nos grãos de café}

O teor de água nos grãos de café foi avaliado com a utilização da estufa, onde os grãos foram submetidos a uma temperatura de $105 \pm 3^{\circ} \mathrm{C}$, durante 24 horas (BRASIL, 1992).

Ciênc. agrotec., Lavras, v. 29, n. 5, p. 1015-1020, set./out., 2005 


\section{Condutividade elétrica (CE) e Lixiviação de potássio (LK)}

As metodologias de determinação da condutividade elétrica e lixiviação de potássio nos grãos de café foram realizadas segundo adaptação da metodologia proposta por Prete (1992), conforme procedimento abaixo.

Quatro amostras de 50 grãos de cada parcela foram pesadas e imersas em $75 \mathrm{~mL}$ de água deionizada (no interior de copos plásticos de $180 \mathrm{~mL}$ de capacidade) e colocadas em estufa ventilada a $25^{\circ} \mathrm{C}$. Após o período de embebição de 5 horas, as soluções sem os grãos de café foram vertidas para outro recipiente, onde se realizou a leitura da condutividade elétrica em condutivímetro. Os resultados foram ser expressos em $\mu \mathrm{S} . \mathrm{cm}^{-1} \cdot \mathrm{g}^{-1}$ de amostra. Imediatamente após a leitura da condutividade elétrica, realizou-se a leitura do potássio lixiviado na solução em fotômetro de chama. Os resultados da quantidade de potássio lixiviado foram expressos em ppm.

Separação por tamanho dos grãos de café para a determinação da CE e LK

Procedimento: $300 \mathrm{~g}$ de café beneficiado (com e sem defeitos) foram passadas em peneiras de crivo circular para separação quanto ao tamanho dos grãos obedecendo a seguinte sequiência decrescente: peneira 20, 19, 18, 17, 16, 15, 14, 13 e 12. Também foi realizada a determinação da amostra controle (sem separação por peneira, ou seja, bica corrida). Após a separação dos grãos em diferentes tamanhos, os grãos retidos em cada peneira foram pesados e foi calculada a porcentagem de grãos retidos considerando sua relação com o peso total. Procedeu-se então a determinação da condutividade elétrica e lixiviação de potássio.

\section{Separação dos grãos defeituosos para a determinação da CE e a LK}

Procedimento: Foram separados manualmente os grãos verdes, brocados, ardidos e pretos. Após a separação e contagem de 4 repetições de 50 grãos de cada tipo de defeito os grãos foram pesados para a determinação da CE e LK.

\section{Análise Estatística}

Os resultados de condutividade elétrica e lixiviação de potássio de cada fator analisado foram submetidos à análise de variância e para comparação entre médias utilizou-se o teste de Scott \& Knott a $5 \%$ de probabilidade.

\section{RESULTADOS E DISCUSSÃO}

\section{Tamanho dos grãos de café}

Na Tabela 1 verifica-se que nas amostras em que não foram retirados os grãos defeituosos, a separação por tamanho implica também em separação das amostras por peso, condutividade elétrica e lixiviação de potássio. Observou-se que os grãos de café retidos nas menores peneiras apresentaram os maiores valores de condutividade elétrica e lixiviação de potássio, além de menor peso. Os grãos retidos na peneira 12 apresentaram os maiores valores de condutividade elétrica e lixiviação de potássio. É interessante ressaltar que a porcentagem de retenção de grãos nessa peneira é relativamente baixa, sendo de $0,67 \%$. Prete (1992),também verificou valores elevados de condutividade elétrica nessa classe de tamanho, o que refletiria em um estádio de deterioração mais avançado ou um maior grau de imaturidade. Trabalhos de Teixeira et al. (1974), reforçam a idéia de que a concentração de defeitos aumenta à medida que as classes de tamanho de grãos diminuem.

$\mathrm{Na}$ amostra em que não houve separação por tamanho (bica corrida), verificaram-se valores de peso e condutividade elétrica semelhantes aos grãos separados pela peneira 16. Em relação à lixiviação de potássio, os valores foram semelhantes às peneiras 16 até a peneira 19 , que não diferiram estatisticamente. Entretanto, Prete (1992) cita que uma separação do café em classes de tamanho (peneiras) não implica em separação em níveis de condutividade elétrica, discordando dos resultados aqui apresentados para as amostras em que não houve a retirada dos defeitos. Já nas amostras em que houve a retirada de defeitos (Tabela 2) não se verificou a separação em níveis de CE, apresentando todas as separações por peneira valores semelhantes, com exceção da peneira 19, que apresentou menores valores em relação às demais.

\section{Grãos defeituosos}

Pela Tabela 3 observa-se que os grãos normais, ou seja, sem defeitos, apresentaram maior peso em relação aos grãos defeituosos. Esses apresentaram a seguinte escala decrescente de peso: grãos verdes, brocados, ardidos e pretos.

Em relação aos valores de condutividade elétrica e lixiviação de potássio, verificou-se que os grãos normais apresentaram os menores valores diferindo estatisticamente dos grãos defeituosos. Os maiores valores de CE e LK foram verificados nos defeitos ardidos e pretos.

Verifica-se a seguinte ordem crescente de condutividade elétrica: grãos normais, verdes, brocados e ardidos semelhantes aos pretos. Em relação à lixiviação de potássio, verifica-se o mesmo comportamento, com exceção dos grãos verdes e brocados que apresentaram valores semelhantes. Verificou-se conformidade com as observações relatadas por Pereira (1997) e Prete (1992), nas quais a intensidade da CE e LK aumentam com a gravidade do defeito do café. 
TABELA 1 - Porcentagem de retenção, peso de 50 grãos, condutividade elétrica (C.E.) e lixiviação de potássio (L.K.) de grãos de café previamente separados quanto ao tamanho de amostras sem a retirada de defeitos.

\begin{tabular}{|c|c|c|c|c|}
\hline $\begin{array}{l}\text { Tamanho } \\
\text { (peneira) }\end{array}$ & $\begin{array}{l}\text { Porcentagem de } \\
\text { retenção }(\%)\end{array}$ & $\begin{array}{c}\text { Peso de } 50 \text { grãos } \\
\text { (g) }\end{array}$ & $\begin{array}{c}\text { C.E. } \\
\left(\mu S . c^{-1} \cdot g^{-1} \text { de amostra }\right)\end{array}$ & $\begin{array}{l}\text { L.K. } \\
\text { (ppm) }\end{array}$ \\
\hline 19 & 4,80 & $8,23 \mathrm{a}$ & $189,35 \mathrm{e}$ & $54,13 d$ \\
\hline 18 & 14,44 & $7,79 \mathrm{~b}$ & $202,88 \mathrm{e}$ & $53,62 d$ \\
\hline 17 & 28,68 & $7,20 \mathrm{c}$ & $188,58 \mathrm{e}$ & $54,80 \mathrm{~d}$ \\
\hline 16 & 24,37 & $6,36 \mathrm{~d}$ & $220,73 d$ & $52,69 d$ \\
\hline 15 & 15,26 & $5,78 \mathrm{e}$ & $242,63 c$ & $59,20 \mathrm{c}$ \\
\hline 14 & 8,54 & $5,31 \mathrm{f}$ & $247,80 \mathrm{c}$ & $62,02 \mathrm{c}$ \\
\hline 13 & 3,25 & $4,46 \mathrm{~g}$ & $293,38 b$ & $74,79 b$ \\
\hline 12 & 0,67 & $3,80 \mathrm{~h}$ & $363,58 \mathrm{a}$ & $84,01 \mathrm{a}$ \\
\hline Bica corrida & & $6,06 \mathrm{~d}$ & $225,98 \mathrm{~d}$ & $53,80 \mathrm{~d}$ \\
\hline $\mathrm{CV}(\%)$ & & 4,19 & 6,18 & 8,37 \\
\hline
\end{tabular}

Médias seguidas pela mesma letra, na coluna, não diferem entre si pelo teste de Scott \& Knott ao nível de $5 \%$ de probabilidade.

TABELA 2 - Porcentagem de retenção, peso de 50 grãos, condutividade elétrica (C.E.) e lixiviação de potássio (L.K.) de grãos de café previamente separados quanto ao tamanho de amostras sem defeitos.

\begin{tabular}{|c|c|c|c|c|}
\hline $\begin{array}{c}\text { Tamanho } \\
\text { (peneira) }\end{array}$ & $\begin{array}{l}\text { Porcentagem de } \\
\text { retenção }(\%)\end{array}$ & $\begin{array}{c}\text { Peso de } 50 \text { grãos } \\
\text { (g) }\end{array}$ & $\begin{array}{c}\text { C.E. } \\
\left(\mu \mathrm{S} . \mathrm{cm}^{-1} . \mathrm{g}^{-1} \text { de amostra }\right)\end{array}$ & $\begin{array}{l}\text { L.K. } \\
\text { (ppm) }\end{array}$ \\
\hline 19 & 4,80 & $8,66 a$ & $138,38 b$ & $47,38 b$ \\
\hline 18 & 14,44 & $7,90 \mathrm{~b}$ & $210,53 a$ & $52,72 \mathrm{a}$ \\
\hline 17 & 28,68 & $7,24 \mathrm{c}$ & $216,66 a$ & $51,12 b$ \\
\hline 16 & 24,37 & $6,50 \mathrm{e}$ & $221,77 \mathrm{a}$ & $48,65 b$ \\
\hline 15 & 15,26 & $6,10 \mathrm{f}$ & $227,87 a$ & $54,64 \mathrm{a}$ \\
\hline 14 & 8,54 & $5,70 \mathrm{~g}$ & $236,70 a$ & $57,66 a$ \\
\hline 13 & 3,92 & $5,27 \mathrm{~h}$ & $220,55 a$ & $53,08 \mathrm{a}$ \\
\hline Bica corrida & & $6,77 \mathrm{~d}$ & $225,98 \mathrm{a}$ & $53,80 \mathrm{a}$ \\
\hline $\mathrm{CV}(\%)$ & & 2,51 & 4,43 & 6,38 \\
\hline
\end{tabular}

Médias seguidas pela mesma letra, na coluna, não diferem entre si pelo teste de Scott \& Knott ao nível de $5 \%$ de probabilidade.

Segundo Coelho \& Pereira (2002), entre os vários fatores que afetam a qualidade do café destaca-se a presença de grãos defeituosos, principalmente os verdes, ardidos e pretos, sendo conhecida a influência prejudicial destes no aspecto, torração e principalmente na qualidade da bebida do café. Coelho \& Pereira (2002) e Pereira (1997) verificaram que a inclusão de grãos verdes, ardidos e pretos alterou significativamente as características químicas do café, classificado como estritamente mole. Ainda segundo Pereira (1997), verifica-se redução na qualidade do café com a adição dos grãos defeituosos pretos, verdes e ardidos, ressaltando que a qualidade encontra-se intimamente relacionada à composição química e que as alterações ocasionadas pela inclusão de grãos defeituosos poderão refletir-se nas características sensoriais destes após a torração.

Ciênc. agrotec., Lavras, v. 29, n. 5, p. 1015-1020, set./out., 2005 
TABELA 3 - Peso de 50 grãos, condutividade elétrica (C.E) e lixiviação de potássio (L.K.) de grãos de café normais e defeituosos.

\begin{tabular}{|c|c|c|c|}
\hline $\begin{array}{l}\text { Tamanho } \\
\text { (peneira) }\end{array}$ & $\begin{array}{c}\text { Peso de } 50 \text { grãos } \\
\text { (g) }\end{array}$ & $\begin{array}{c}\text { C.E. } \\
\left(\mu \text { S.cm }{ }^{-1} \cdot g^{-1} \text { de amostra }\right)\end{array}$ & $\begin{array}{l}\text { L.K. } \\
(\mathbf{p p m})\end{array}$ \\
\hline Sem defeitos & $6,88 \mathrm{a}$ & $227,58 d$ & $50,35 \mathrm{c}$ \\
\hline Verdes & $6,46 \mathrm{~b}$ & $307,63 \mathrm{c}$ & $94,24 b$ \\
\hline Brocados & $4,83 \mathrm{c}$ & $361,50 \mathrm{~b}$ & $91,80 \mathrm{~b}$ \\
\hline Ardidos & $4,50 \mathrm{~d}$ & $539,80 \mathrm{a}$ & $146,45 \mathrm{a}$ \\
\hline Pretos & $3,47 \mathrm{e}$ & $511,70 \mathrm{a}$ & $147,25 \mathrm{a}$ \\
\hline $\mathrm{CV}(\%)$ & 3,07 & 5,90 & 7,43 \\
\hline
\end{tabular}

Médias seguidas pela mesma letra, na coluna, não diferem entre si pelo teste de Scott \& Knott ao nível de $5 \%$ de probabilidade.

Illy et al. (1982) realizaram estudos sobre as características de reflectância dos grãos defeituosos, visando sua eliminação dos lotes de café através da seleção eletrônica pela cor. Os autores estudaram as características da superfície e das células dos grãos defeituosos, verificando que a desorganização celular aumenta dos grãos verdes para os ardidos e destes para os preto-verdes. Essa desorganização celular permite que a água penetre e se difunda com maior facilidade com o aumento da intensidade dos danos celulares. Essa hipótese tem confirmação nos resultados obtidos por Prete (1992), em que os grãos normais passaram de $12 \%$ para 38,49\% de umidade após 3,5 horas de embebição enquanto que os grãos verdes, ardidos, pretos e pretoverdes, passaram de $12 \%$ para $57,78 \% ; 65,77 \% ; 69,43 \%$ e $74,53 \%$ de umidade, respectivamente.

Percebe-se então que os defeitos influenciam de forma significativa às determinações de condutividade elétrica e lixiviação de potássio, podendo comprometer uma interpretação adequada das características de um lote de café. Esse fato acentua a importância de se calibrar esses métodos com a finalidade de se reduzir interferências que possam resultar em interpretações errôneas dos grãos de café que estão sendo analisados.

\section{CONCLUSÃO}

A presença de grãos defeituosos influencia de maneira significativa as determinações de condutividade elétrica e lixiviação de potássio de exsudatos de grãos, podendo fornecer interpretações inadequadas quanto à qualidade do café analisado.

\section{REFERÊNCIAS BIBLIOGRÁFICAS}

AMORIM, H. V. Aspectos bioquímicos e histoquímicos do grão de café verde relacionados com a deterioração da qualidade. 1978. 85 f. Tese (Livre Docência em Bioquímica)Escola Superior de Agricultura Luiz de Queiroz, Piracicaba, 1978.

BEDFORD, L. V. Conductivity tests in commercial and hand harvested seed of pea cultivars and their relation to field establishment. Seed Science and Technology, Zurich, v. 2, n. 3, p. 323-335, 1974.

BRASIL. Ministério da Agricultura e Reforma Agrária. Regras para análise de sementes (RAS). Brasília, DF, 1992. 365 p.

CARVALHO, V. D. de; CHAGAS, S. J. de R.; CHALFOUN, S. M. Fatores que afetam a qualidade do café. Informe Agropecuário, Belo Horizonte, v. 18, n. 187, p. 5-20, 1997.

CHAGAS, S. J. de R. Caracterização química e qualitativa de cafés de alguns municípios de três regiões produtoras de Minas Gerais. 1994. 83 f. Dissertação (Mestrado em Ciência dos Alimentos) - Universidade Federal de Lavras, Lavras, 1994.

CLIFFORD, M. N. Chemical and physical aspects of green coffee and coffee products. In: CLIFFORD, M. N.; WILSON, K. C. Coffee, botany: biochemistry and production of beans and beverage. London: Croom Helm, 1985. p. 305-359.

COELHO, K. F.; PEREIRA, R. G. F. A. Influência de grãos defeituosos em algumas características químicas do café cru e torrado. Ciência e Agrotecnologia, Lavras, v. 26, n. 2, p. 375-384, mar./abr. 2002. 
CORTEZ, J. G. Aptidão climática para qualidade da bebida nas principais regiões cafeeiras de Minas Gerais. Informe Agropecuário, Belo Horizonte, v. 18, n. 187, p. 21-26, 1997.

FAVARIN, J. L.; VILLELA, A. L. G.; MORAES, M. H. D.; CHAMMA, H. M. C. P.; COSTA, J. D. Qualidade da bebida de café de frutos cereja submetido a diferentes manejos pós-colheita. Pesquisa Agropecuária Brasileira, Brasília, v. 39, n. 2, p. 187-192, fev. 2004.

GOTARDO, M.; VIEIRA, R. D.; PEREIRA, L. M. A. Teste de condutividade elétrica em sementes de milho. Ceres, Viçosa, v. 48, n. 277, p. 333-340, 2001.

ILLY, E.; BRUMEN, G.; MASTROPASQUA, L.; MAUGHAN, W. Study on the characteristics and the industrial sorting of defective beans in green coffee lots. In: COLÓQUIO CIENTÍFICO INTERNACIONAL SOBRE O CAFÉ, 10., 1982, Salvador. Anais... Salvador: [s.n.], 1982. p. $99-126$.

LOEFFLER, T. M.; TERRONY, D. M.; ECLI, D. B. The bulk conductivity test as an indicator of soybean seed quality. Journal of Seed Technology, Lansing, v. 12, n. 1, p. 37-53, 1988.

MARCOS FILHO, J.; SILVA, W. R.; NOVEMBRE, A. D. C.; CHAMMA, H. M. C. P. Estudo comparativo de métodos para a avaliação da qualidade fisiológica de sementes de soja, com ênfase ao teste de condutividade elétrica. Pesquisa Agropecuária Brasileira, Brasília, v. 25, n. 12, p. 1805-1815, 1990.

PEREIRA, R. G. F. A. Efeito da inclusão de grãos na composição química e qualidade do café (Coffea arábica L.) "estritamente mole". 1997. 96 f. Tese (Doutorado em Ciência dos Alimentos) - Universidade Federal de Lavras, Lavras, 1997.

PRETE, C. E. C. Condutividade elétrica do exsudato de grãos de café (Coffea arabica L.) e sua relação com a qualidade da bebida. 1992. 125 f. Tese (Doutorado em Fitotecnia) - Escola Superior de Agricultura Luiz de Queiroz, Piracicaba, 1992.

ROMERO, J. C. P.; ROMERO, J. P.; GOMES, F. P. Condutividade elétrica (CE) do exsudato de grãos de Coffea arabica em 18 cultivares analisados no período de 1993 a 2002. Revista de Agricultura, Piracicaba, v. 78, n. 3, p. 293302, dez. 2003.

TEIXEIRA, A. A.; PEREIRA, L. S. P.; PINTO, J. C. A. Classificação de café: noções gerais. Rio de Janeiro: IBC/ GERCA, 1974. 88 p.

WOODSTOCK, L. W. Physiological and biochemical tests for seed vigor. Seed Science and Technology, Zurich, v. 1, n. 1, p. $127-157,1973$.

Ciênc. agrotec., Lavras, v. 29, n. 5, p. 1015-1020, set./out., 2005 